\title{
GIS based risk assessment of oil and gas infrastructure in Sindh, Pakistan
}

\author{
Syed Talha Tirmizi*, Syed Rizwan Ul Haq Tirmizi \\ Email: talhatirmizi@outlook.com
}

\begin{abstract}
Being the lifeblood of the modern world economy, oil has been the most immensely produced, expended and traded commodity for decades. Due to the increasing prominence of oil, the security of its infrastructure and assets has become a global concern. The high cost of the infrastructure makes it the principal target for terrorist attacks and theft. In the present study, Geographic Information System (GIS) has been utilized for the prediction of high risk areas indicating the vulnerability of the infrastructure and assets, by spatial analysis. Sindh, being the richest province of Pakistan in natural resources of gas, petrol and coal, is confronting a deteriorating law and order situation. The present study infers to provide support for the safeguarding of the oil and gas industry in Sindh, Pakistan from imminent and future threats.
\end{abstract}

Keywords: Oil and Gas Industry, GIS, Spatial Analysis.

\section{INTRODUCTION}

Sindh is one of the four provinces of Pakistan and is the second largest province with capital in Karachi, which is not only the most populous metropolis of Pakistan but also a commercial hub. The Province of Sindh forms the lower Indus basin and lies between 23 to 35 degree and 28-30 degree, north latitude and 66-42 and 71-1-degree east longitude. It covers 1, 40, 915 square $\mathrm{km}$ and is about as large as England. Though chiefly an agricultural province, the oil and gas production in Sindh constitutes of a considerable proportion in country's total production. Despite oil and gas being an important factor of the country's economy, terrorism in Sindh has also become a destructive phenomenon over the decades. With increasing oil and gas discoveries, terrorism and theft have developed as a challenge for the oil exploration companies. Sindh remains the second worst terrorism-affected region across Pakistan in terms of fatalities (Sindh Assessment, 2015). The research is concentrated on the oil and gas infrastructure security aspects in Sindh, Pakistan. The oil theft and terrorism have been observed in the region in recent decades. The large sum of revenue generated by the industry and the interdependency of the systems involved in it, makes it the principal target for the terrorist groups. There is even a potential for pipelines being drilled into and oil collected by the rebel groups and sold to other countries on the black market. The tumultuous state of Sindh, has projected imminent threats to the operations of the oil and gas companies in the province, a solution to which has become the basis for this study. To help prevent the attacks on Oil and Gas (OG) assets, a GIS solution was implemented. According to Cova (1999), GIS is attaining approval in contrast with the traditional approaches of risk assessment. Risk assessment has emerged as a result of worldwide interest in different aspects of hazards. Risk is often defined as possible loss from the potentially harmful phenomena in the prescribed area. Risk is analyzed by taking into account the components such as hazard, defined as the pre-disaster situation where contingency of disaster prevails, and vulnerability often referred to the human built environment. Risk assessment forms an integral module in disaster management, in the development of contingency plans and improving the response time during terrorist attacks or theft. Ingleton urged that risk combines information on the nature hazard with information on vulnerability of the targets. It is helping to clarify decision making and the development of mitigation strategies (Ingleton, 1991-2000). Alexander declared that hazard is the pre-disaster situation in which contingency of disaster prevails, primarily due to self-reliant vulnerability of the human population (Alexander, 1993). The above-mentioned studies maintain the same norm that risk is cumulative outcome of the hazard and vulnerability. In the present study, GIS is imperatively utilized to measure risk; the development of the risk model was to exhibit the peril from the oil and gas infrastructure security context.

\section{METHODOLOGY}

The study involved several technical steps. The foremost step was the composing of the spatial information into a standard geodatabase. The next phase was to perform spatial analysis on the data. The features with-in the geographic database were assigned weights and a risk map was then generated using a combination of ArcGIS tools. ArcGIS 10.1 is a notable application for working with maps, especially when dealing with visualization and spatial information. 
Before evaluating the spatial data, a formula was derived for the risk. Variables were collected which would contribute towards risk. Then these variables were grouped into three categories; Hazard, Vulnerability and Floods. The Hazard group included technological hazard variables which referred to the built environment such as pipelines and fields for both gas and crude oil, refineries etc. The refineries and other plants were grouped together into facilities. Vulnerability included all those features related to the human environment. i.e. cities and urban areas, roads in proximity to populated places and conflicts and social unrest in the province. Conflicts and terrorist attacks data were retrieved from the Armed Conflict Location \& Event Data Project and Global Terrorism Database, respectively. Collins states that if there is no population then even a highly intensive hazard event will not have risk. Similarly, if the likelihood for a hazard event is relative to zero then a population having no defensive resources will possess no risk (Collins, 2009). The 2011 floods in Sindh caused the most devastating destruction throughout the province. The floods caused considerable damage; an estimated 434 civilians were killed, with 5.3 million people and 1,524,773 homes affected (Rana, Z.A.S, 2011). Floods are frequent in Sindh. Thus, we have included its risk in the third group. These three groups led to the derivation of a generalized formula which accounts towards the evaluation of the final risk map. The risk formula is mentioned below:

Risk $=R\left(H_{E}, V_{E}\right)+F_{E}$

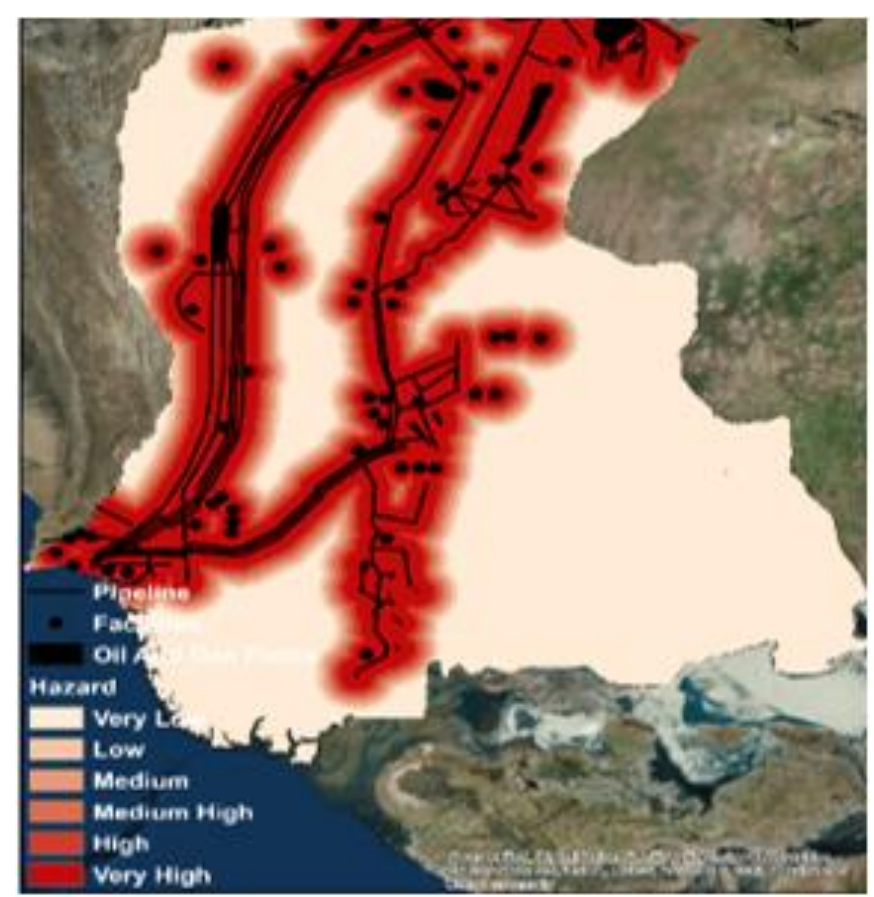

Figure 1. Hozard map

$\mathrm{H}$ is the function of hazard and $\mathrm{V}$ is the function of vulnerability while $\mathrm{F}$ is the function of flood risk. Here Risk is taken as the function of the product of Hazard and Vulnerability with function $F_{E}$ being added to it. By determining the scores of all features and assigning them to their appropriate location, a risk map can then be derived. The weights were assigned from 1-6. These weights gave much flexibility in the determination of the area. The above mentioned groups were modelled and maps were produced (Figure 1).

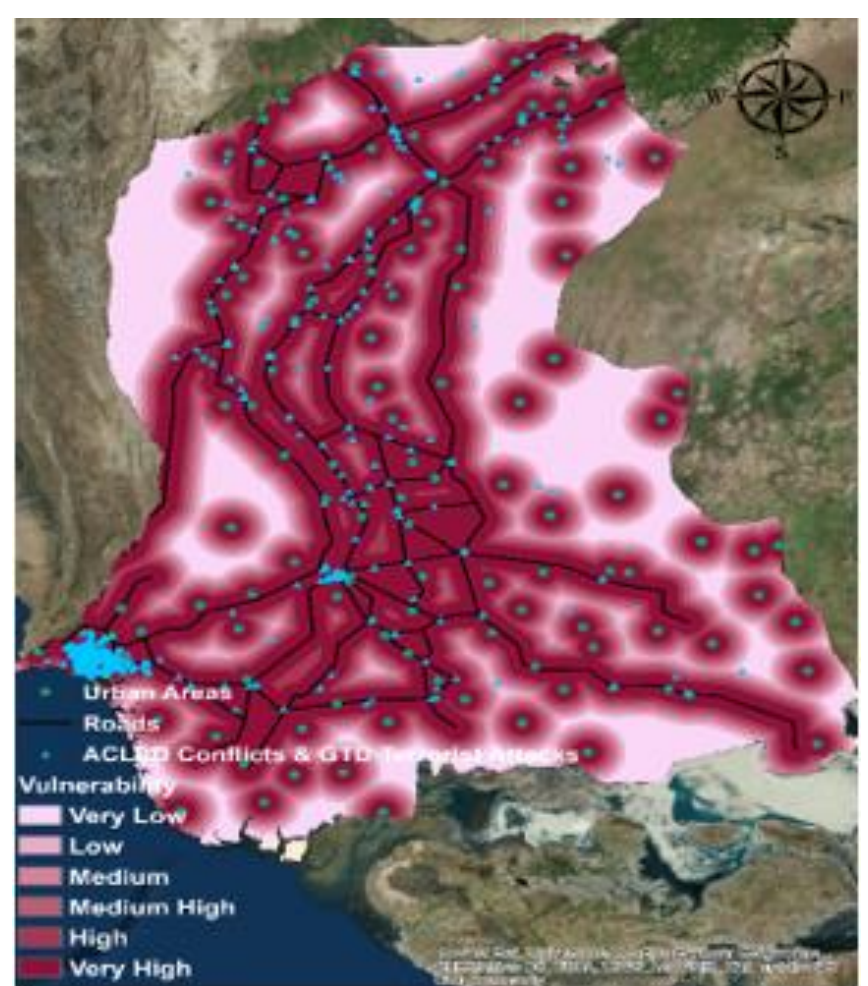

Figure 2. Vulnerability map

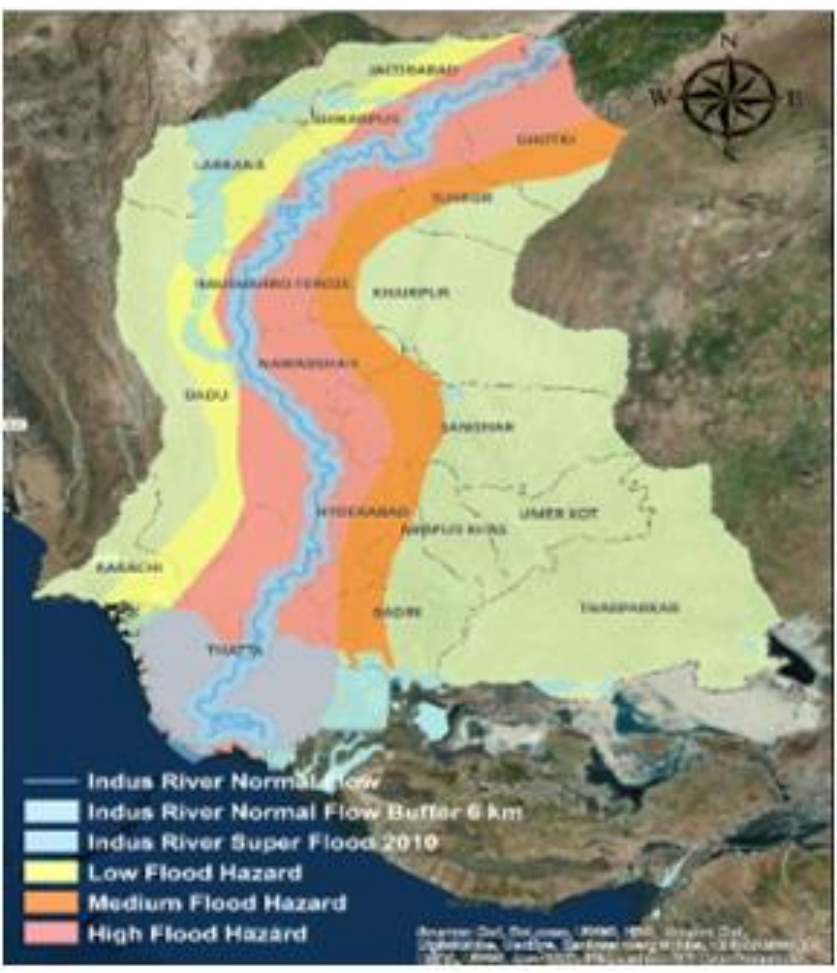

Figure 3. Flood vulnerable areas

In Figure 1, the Hazard model included, oil and gas pipelines, facilities and oil and gas fields. The geographic data was retrieved from the energy map 2014 provided by the Pakistan Petroleum Information Service (PPIS, 2014). The Buffer tool was performed over the features with the distance of $5 \mathrm{~km}$. This defined the proximity of the features to their surroundings. The obtained results were then merged into a single layer over which the multi-ring buffer tool was then performed with the distance ranging from $5 \mathrm{~km}$ to $15 \mathrm{~km}$. This 
defined the proximity of the features. Weightings were then assigned according to the distance from the features. The weights ranged from 1 to 5 . The Polygon to Raster tool was then utilized after which an additional risk value, using Reclassify tool, ranging from $1-6$ was given to each feature, with a weight of 1 being allocated to those regions where there was no hazard component. It can be deduced from Figure 1 that the area surrounding the hazard components were more uncertain than those further away. In Figure 2, the Vulnerability model included those features which were related to the human environment e.g. urban areas including cities, roads and most importantly conflicts and terrorist attacks. The social unrest information was collected from two renowned projects, Armed Conflict and Location Event Database (https://www.acleddata.com/), from 2015 - 2016 and Global Terrorism Database (https://www.start.umd.edu/gtd/) from 1970 - 2015. Global Terrorism Database (GTD) is an open source database of terrorist events that occurred in the world during the period of 1970 to 2015, with more information updated in the coming time. Armed Conflict and Location Event Database (ACLED) is a wide-ranging public accumulation of political vehemence and protest data for developing states. The database was downloaded from the official website and only those events that had occurred in Sindh, were selected from the database. A number of GIS operations, as same for the hazard model, were performed on the vulnerability map such as buffers, merge, multi-ring buffers, dissolves and clips. The spatial join tool was also used in order to merge all the events obtained from the GTD and ACLED databases into a single layer and the count tool was used to produce one more layer called the top 9 unrest districts. These districts were those that had the most occurrences of the events related to terrorism and conflicts. Buffer was performed over the top 9 districts with a distance of $5 \mathrm{~km}$. This layer was also merged with the rest of the features as it highlighted those areas of other districts which were vulnerable to social unrest. Finally, a raster layer was developed as displayed, in figure 2, for the vulnerability model, which was also assigned weights of 1-6. The vulnerability model showcased those parts of the region which were related to the human environment, such as proximity to cities and roads, social unrest etc. It can be asserted that those areas which had the most infrastructure were likely to possess more risk than those which were underdeveloped. Figure 3 shows the flood map which exhibit the risk of floods pertaining to different areas of Sindh. A $6 \mathrm{~km}$ buffer was produced along the indus river. The area around the river indus was distributd into three zones, namely low, medium and high flood hazard. The map has also highlighted the regions which were adversely affected by the Indus river flood of 2010, which caused an estimated 434 deaths, with 5.3 million people and 1,524,773 homes affected (Rana, Z.A.S, 2011). Floods are frequent in most parts of Sindh that cause damage to pipelines and other infrastructures. This welldistributed data provided a much wider perception for the identification of the flood hazard regions in Sindh. The flood map was retrieved from the Sindh - Flood Hazard Map by USAID (USAID, 2012). Model maps were developed in Raster. The most important phase was the last step which involved the use of the Raster Calculator Tool for the multiplication of vulnerability raster and hazard raster and then the addition of the flood raster from the tools of Spatial Analyst and Map Algebra. The classification scheme used in the final risk map is the same as 1-6. The output Risk Map is keenly discussed in the following section.

\section{RESULTS AND DISCUSSION}

The output risk map had weightage ranging from 1 to 42 , which can be termed as intermediate risk map as displayed in figure 5. The method employed for determining the ranges in classification scheme was natural break method, shown in figure 4. In natural break method, the class breaks are determined by identifying the best group having similar values and that maximize the differences between the classes

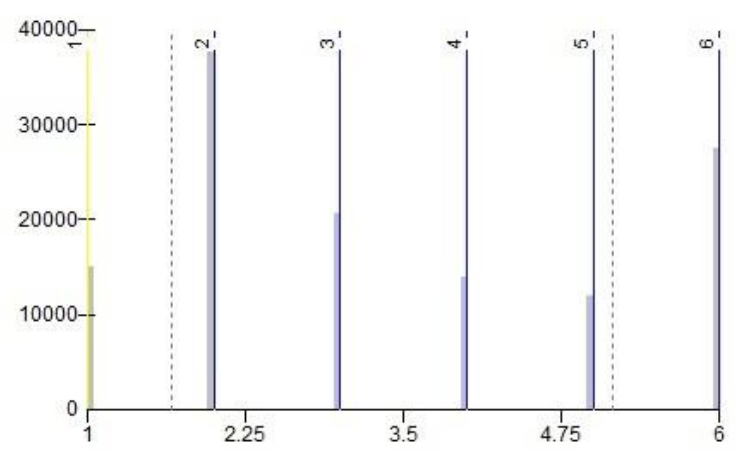

Figure 4. Natural break classification

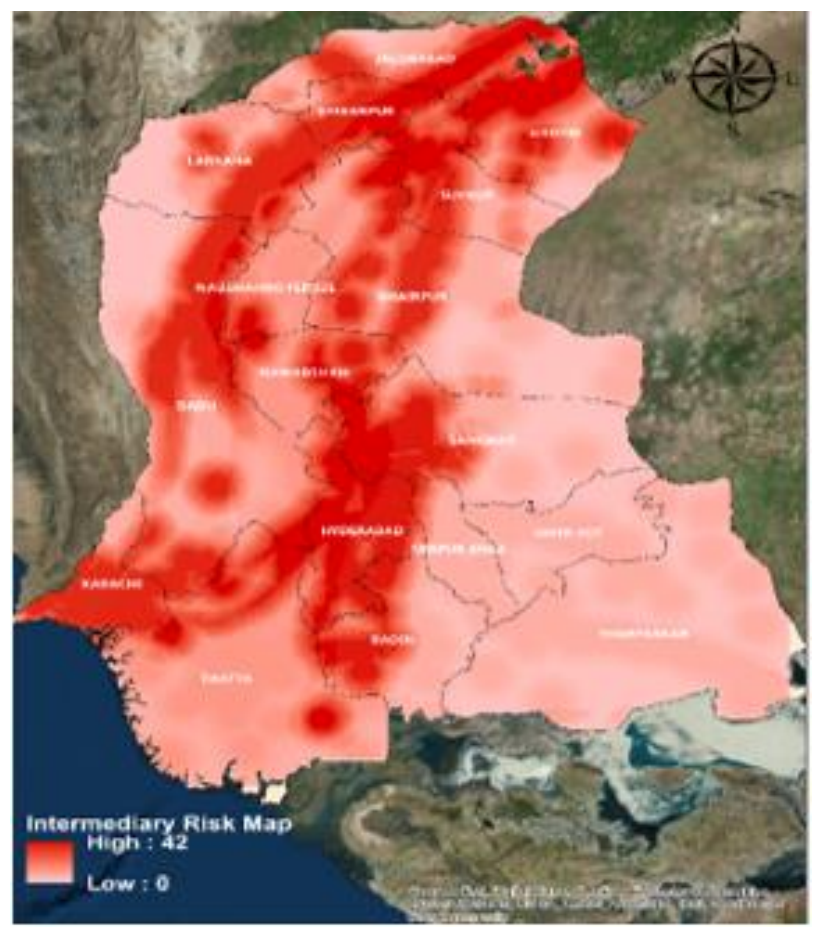

Figure 5. Intermediate risk map

The range of classification was divided into six classes whose boundaries were set where there was considerable difference in the data values. The classes were defined as: $36-$ 42 (Very High), 27-35 (High), 18-26 (Medium High), 10-17 (Medium), 4-9 (Low), and 1-3 (Very Low). Figure 4 demonstrates the distribution of data values into their respective classes. The sixth class, designated as Very High, represents high number of data values after the Low class. The standard deviation in the risk map is 1.744012 .

The prescribed classification scheme helped in enhanced understanding of the high risk areas. The final risk map is shown in Figure 6. 


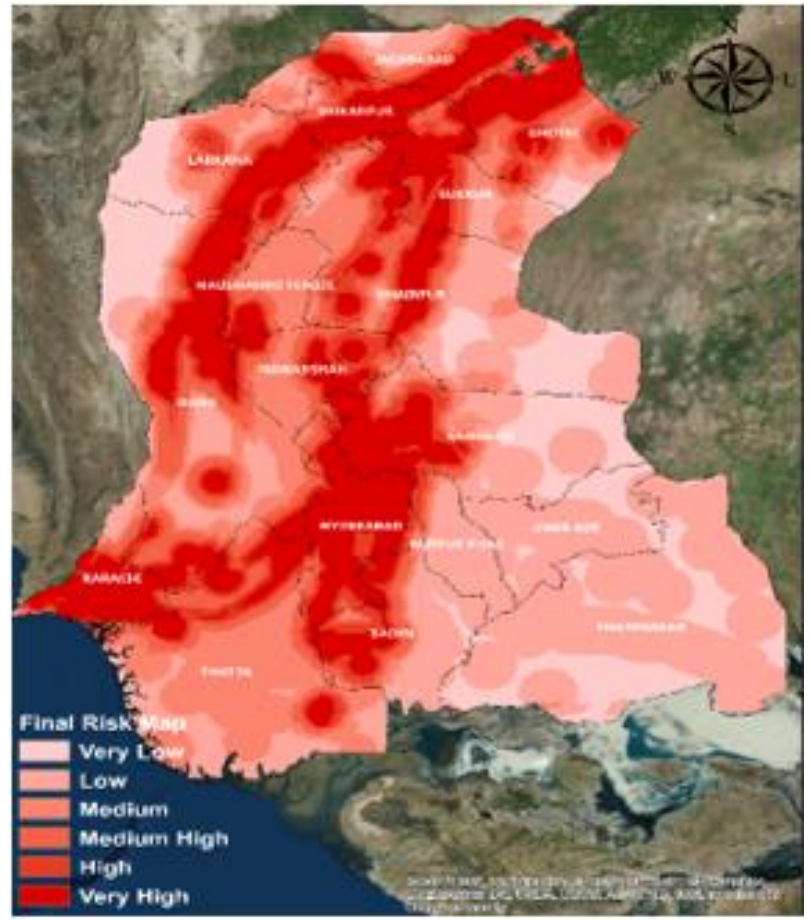

Figure 6. Final risk map

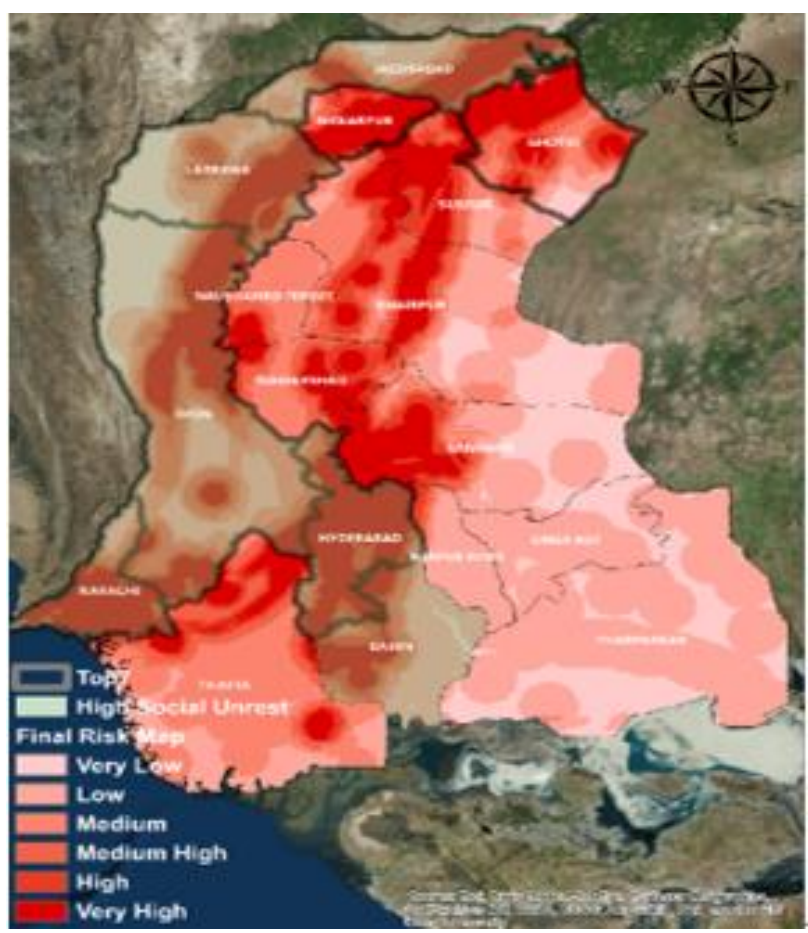

Figure 7. Top 7 high risk districts

There are a number of observation that can be understood from the result. The foremost is that the districts that pose high risk are Karachi, Hyderbad, Dadu, Larkana, Shikarpur, Jacobabad, Ghotki, Sukkur and Khairpur. This can even easily be determined through visual inspection. The urban and financial centres of the province of Sindh e.g. Karachi and Hyderabad are also at high risk. The second observation is that those districts which are at high risk have high levels of hazard and vulnerability. This is due to the multiplication between the hazard and vulnerability as per the formula. Even though districts including Thatta, Badin and Umerkot do not have oil and gas infrastructure but still they possess some risk. If in future, any oil field is formed in those areas, then most probably the risk will increase in the concerned districts. The output risk map, if compared with the social unrest districts, shows that those districts which have high social unrest also possess high risk. This is illustrated in Figure 7.

In Figure 7, the districts that had the highest number of conflicts and terrorist attacks are highlighted green and those districts that show high risk have thick borders. After a cautious examination of Figure 7, it can be inferred that the districts adjacent to the Baluchistan border possess more risk. Baluchistan despite being rich in natural resources, has always been the least developed province of Pakistan.

Due to the deteriorating law and order situation of Baluchistan, its consequential influence is also observed in the neighboring provinces. This is the reason why the districts bordering Baluchistan are at high risk.

Table 1. District wise comparison of risk

\begin{tabular}{|c|c|c|c|c|c|}
\hline & \multirow{2}{*}{ District } & \multirow{2}{*}{$\begin{array}{l}\text { District } \\
\text { Area } \\
\text { Sq. km. }\end{array}$} & \multicolumn{3}{|c|}{ High \& Very High } \\
\hline & & & $\begin{array}{l}\text { Percen } \\
\text { Risk }\end{array}$ & $\begin{array}{l}\text { Area Risk } \\
\text { sq. } \mathrm{km} \text {. }\end{array}$ & We \\
\hline 1 & Badin & 6740.604 & 12.16 & 554.504 & High \\
\hline 2 & Dadu & 18895.754 & 31.56 & 598.730 & Very High \\
\hline 3 & Ghotki & 6427.976 & 18.71 & 343.546 & Very High \\
\hline 4 & Hyderabad & 5575.581 & 20.42 & 273.022 & Very High \\
\hline 5 & Jacobabad & 5464.156 & 11.93 & 457.937 & High \\
\hline 6 & Khairpur & 15920.501 & 22.28 & 714.554 & Very High \\
\hline 7 & Larkana & 7411.551 & 14.02 & 528.727 & Very High \\
\hline 8 & Karachi & 65.487 & 10.23 & 6.404 & Very High \\
\hline 9 & Mirpurkhas & 2977.740 & 1.72 & 1734.267 & Low \\
\hline 10 & Nausharo & 3036.508 & 3.27 & 928.891 & Medium \\
\hline 11 & Nawabshah & 4496.875 & 12.69 & 354.280 & High \\
\hline 12 & Sanghar & 10765.925 & 16.04 & 671.399 & Very High \\
\hline 13 & Shikarpur & 2560.190 & 9.83 & 260.507 & Very High \\
\hline 14 & Sukkur & 5199.300 & 15.07 & 344.999 & Very High \\
\hline 15 & Tharparkar & 19890.993 & 0.00 & 0.000 & Very Low \\
\hline 16 & Thatta & 16988.447 & 18.66 & 910.272 & Very High \\
\hline 17 & Umerkot & 5503.499 & 0.00 & 0.000 & Very Low \\
\hline
\end{tabular}
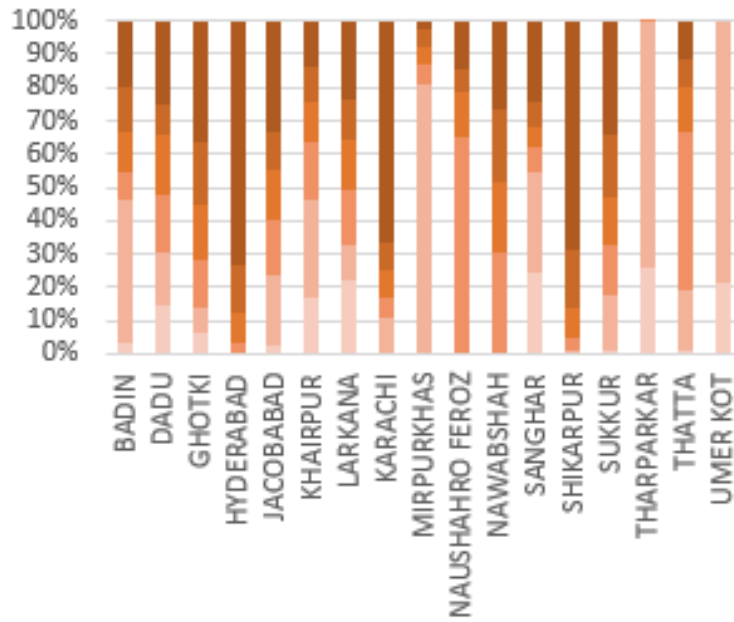

$$
\begin{aligned}
& \text { Very Low } \quad \text { Low Medium } \\
& \text { घ Medium-High } \text { a High } \quad \text { Very High }
\end{aligned}
$$

Figure 8. Graphical representation of risk 
According to international assessments, Baluchistan has 6 trillion barrels of oil in onshore/offshore, and 19 trillion cubic feet gas reserves (Popalzai, 2015). Considering the complicated situation of Baluchistan, risk assessment has also become a dire need there, which would be covered in future endeavor. Even if there is no hazard or vulnerability elements in an area, still risk persists, due to unpredicted possibilities. The table 1 provides the comparison of the High and Very High risk and the affected area in district wise order. The mean area at risk per district is 510.7 sq. km. The district which possessed the most risk in terms of area is Dadu, with a risk of 31.56 percent but its area under risk is only 578.730 sq. km. The figure 7 represents the graphical demonstration of risk in Sindh, with risk calibrated in percentages over the six classes. The diagram clearly demonstrates Karachi, Hyderabad, Thatta and Shikarpur at high risk. Thus risk assessment offers contingency planning whilst keeping in view the areas prioritized on the level of jeopardy.

\section{LIMITATIONS}

There were some limitations in the study, the unavailability of the data being the major problem. GIS integrated data of oil and gas infrastructure could have contributed to the study more precisely. There is a dire need for conflict and terrorist attacks monitoring cell in the region which could monitor the incidents in a more precise and organized manner. Instead of relying on foreign projects for the data, government should install regional organizations for the accumulation of the audited information related to oil and gas terrorism. Online surveying, reveals that there has been negligible prior research based on the topic of the present study in Pakistan. With more oil wells being discovered, the risk assessment should be keenly studied as to provide a theoretical groundwork in analyzing the vulnerability of the oil and gas working sites.

\section{CONCLUSION}

The present study has demonstrated the risk assessment of oil and gas infrastructure as a requisite paradigm which stresses a pluralistic approach towards contingency forecasting. The study has also provided a framework which will form an integral component in prioritizing areas for the establishment of any future oil and gas fields.

\section{REFERENCES}

[1] Alexander D. (1993). Natural Disasters, New York: Chapman and Hall.

[2] Collins T.G. (2009). Vulnerability to environmental hazards in the Ciudad Juárez (Mexico)-El Paso (USA) metropolis: A model for spatial risk assessment in transnational context, Applied Geography, Elsevier, Vol. 29, No. 3, pp. 448-461.

[3]. Cova T. (1999). GIS in emergency management, In: Geographical Information Systems: Principles, Techniques, Applications, and Management, P.A. Longley, M.F. Goodchild, D.J. Maguire, D.W. Rhind (eds.), John Wiley \& Sons, New York. West Sussex, England: Wiley.

[4] Ingleton J. (1991-2000). Natural disaster management, international decade for natural disaster reduction. (IDNDR) (Leicester: Tudor Rose Holdings Limited, 1999).

[5] Popalzai S.S. (2015). Development of energy resources - prospects in the province of baluchistan, Pakistan Energy Forum 2015.

[6] PPIS. (2014). Infrastructure Energy Map 2014. Pakistan Petroleum Information Service.

[7] Rana Z.A.S. (2011). Sindh rains: Govt scrambles as UN prepares to launch aid appeal. The Express Tribune. Retrieved from https://ribune.com.pk/story/251425/floods-worsen270-killed-officials/Sindh Assessment. (2015). Retrieved from South Asia Terrorism Portal: http://www.satp.org/satporgtp/countries/pakistan/sindh /index.html

[8] USAID I. (2012). Sindh- Flood Hazard Map 